\title{
THE MALE GENITALIA OF BLATTARIA. III. BLABERIDAE: ZETOBORINAE.
}

\author{
By Louis M. Roth \\ Pioneering Research Laboratory \\ U. S. Army Natick Laboratories \\ Natick, Massachusetts oI 760
}

In this paper I shall illustrate and characterize the male genitalia of 9 genera of blaberids which belong in the subfamily Zetoborinae. These genera are Capucina Saussure, Lanxoblatta Hebard, Phortioeca Saussure, Phortioecoides Rehn, Schistopeltis Rehn, Schizopilia Burmeister, Tribonium Saussure, Zetobora Burmeister, and Zetoborella Hebard. Princis (1960) includes Tribonoidea Shelford in this subfamily but I have been unable to obtain a male of the one species in this genus.

The male genitalia of most species of Blaberidae are characterized by the presence of three phallomeres: a median sclerite, a sclerite on the left, and a retractable hook on the right side. This led McKittrick (1964, p. 72) to conclude that "The male genitalia are extraordinarily uniform throughout the Blaberidae." She also stated (I964, p. 35) that "The male genitalia differ slightly in hook shape and the configuration of the posterior tip of the median sclerite within the Blaberidae, but otherwise show little variation within that group," and on p. I IO "The great uniformity of blaberid male genitalia precludes drawing many conclusions regarding subfamily relationships, except in the case of the Blaberinae and Panesthiinae." "The great uniformity" of the male genitalia of Blaberidae is generally true only for the usual presence of three distinct phallomeres; in certain genera one or more of the phallomeres may be greatly reduced and even absent (e.g. R2 in Panchlora). However, the shapes of the phallomeres, especially the retractable hook $\left(\mathrm{R}_{2}\right)$, prepuce, and L2d are often so distinctive that they may show subfamily, tribal, generic, species Group characteristics, and in some genera may be used for specific determination (Roth and Gurney, 1969; Rcth, 1969, 1970).

\section{Materials and Methods}

The technique for preparing the genitalia has been described in previous papers (Roth, I969, I970). The source of each of the specimens illustrated is given, using the following abbreviations: (ANSP) = Academy of Natural Sciences, Philadelphia; $(\mathrm{BMNH})=$ British 
Museum (Natural History), London; $(\mathrm{CUZM})=$ Copenhagen University, Zoological Museum, Denmark; $(\mathrm{MCZ})=$ Museum of Comparative Zoology, Harvard University; $(\mathrm{N})=$ Natick culture, U. S. Army Natick Labs., Massachusetts; (USNM) = United States National Museum, Washington, D.C.

Geographical collection data, and the names of specialists who identified the specimens, if known, follow these abbreviations. The number preceding the abbreviations refers to the number assigned the specimen and its corresponding genitalia (on a slide) which are depositea in the museums indicated.

\section{Results AND Discussion}

The basic features of the 3 phallomeres of the male genitalia of Zetoborinae are as follows: $\mathrm{R}_{2}$ (hooked right phallomere) is well developed and usually has a subapical incision (Fig. 32). The preputial membrane has a heavily sclerotized area (L2d) which extends dorsally or dorsolaterally to the right of L2vm (Fig. 28); L2d is flattened in the preparations and it should be remembered that it usually extends dorsally. $L_{I}$ is very well developed and various areas are darkly sclerotized (Fig. 30).

Based on the degree of development of L2d and shape of L2vm, the Zetoborinae may be divided into 3 Tribes as follows:

I. Zetoborini (Zetobora and Phortioecoides, Figs. I-5, 22-39). L2d is least developed in this tribe and is a thin sclerotization of the preputial membrane which extends dorsally (Figs. 22, 25, 27, 28, $3 \mathrm{I}, 34,37$ ). The subapical incision of $\mathrm{R}_{2}$ is clearly defined (Figs. $23,29,32,35,38) . L_{I}$ is very similar in all the species in this tribe (Figs. 24, 26, 30, 33, 36, 39).

Hebard (I92I, p. 245) stated that "The differences shown by the forms recognized by us as Tribonidium $[=$ Zetobora $]$ monasticum, transversum, and amplum, may indicate full specific distinction, geographic racial differentiation or, indeed, mere individual variation in a single exceptionally plastic species." The male genitalia of the above 3 species (Figs. 22-26, 28-36) are so similar that they are of little help in distinguishing the various species of Zetobora.

Rehn (1937) placed Phortioecoides in the Panchlorinae. Princis ( I96I) followed Rehn and placed it in the Panchloridae. Princis' Panchloridae is based principally on the shape of the subgenital plate in the male. However, the subgenital plate of the type male of Phortioecoides guarani Rehn (the only species of the genus) is not at all like that of Panchlora. Also the genitalia of Panchlora are 

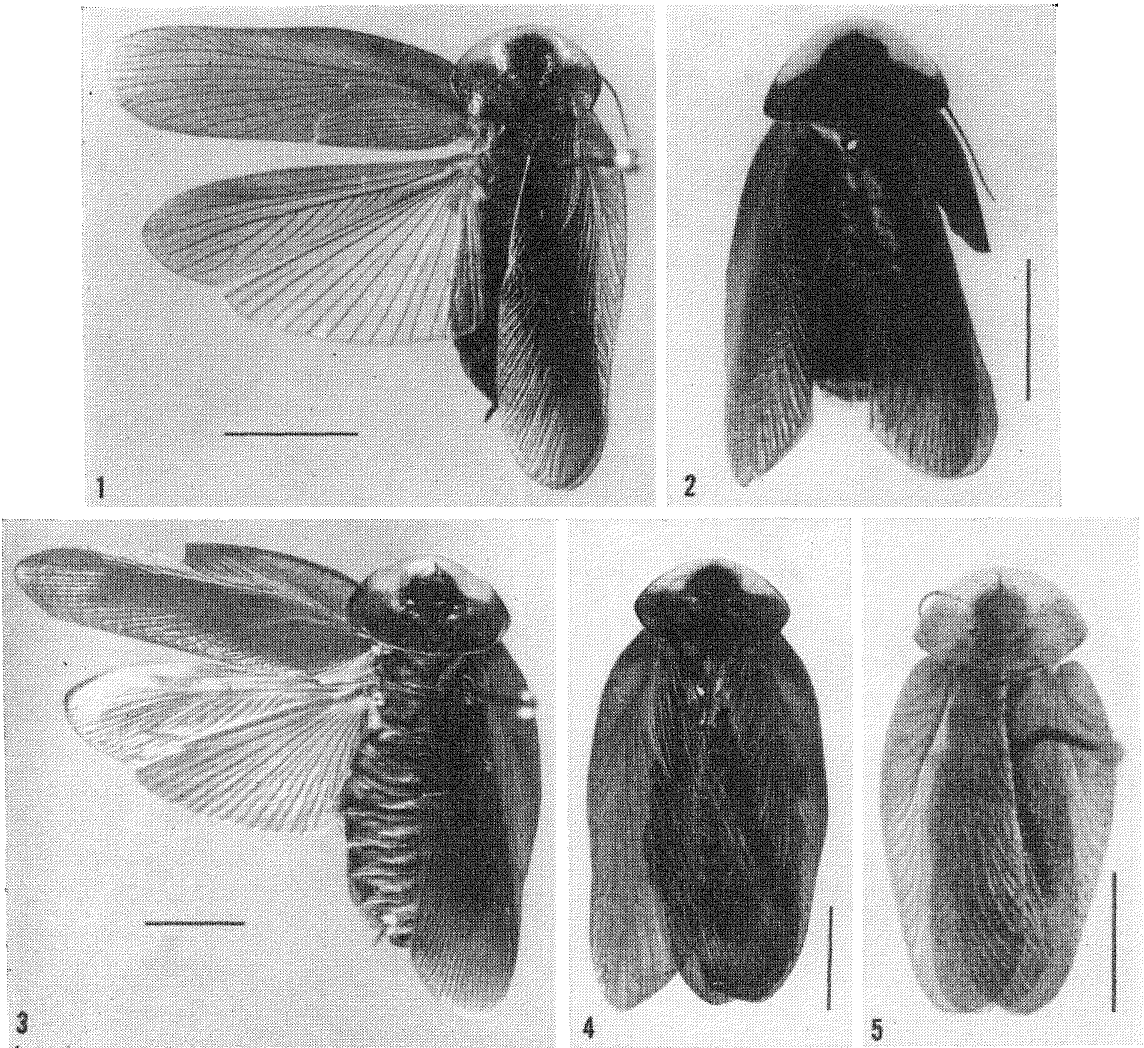

Figs. 1-5. 1. (105 ANSP). Zetobora signaticollis Burm. Curityba, Brazil (det. Hebard). 2. (6 BMNH). Zetobora transversa (Brunner). Rio de Janeiro, Brazil. 3. (106 ANSP). Zetobora ampla (Hebard). Paratype. Montagnes Des Orgues, Prov. de Rio Janeiro, near Tijuca, Brazil. 4. (7 BMNH). Zetobora monastica Sauss. 5. (113 ANSP). Phortioecoides guarani Rehn. Paratype. Horqueta, Paraguay $-40 \mathrm{Km}$ east of Rio $\left(57^{\circ} \mathrm{W}\right.$, $\left.23^{\circ} \mathrm{N}\right) . \quad($ scale $=5 \mathrm{~mm}$. $)$ 

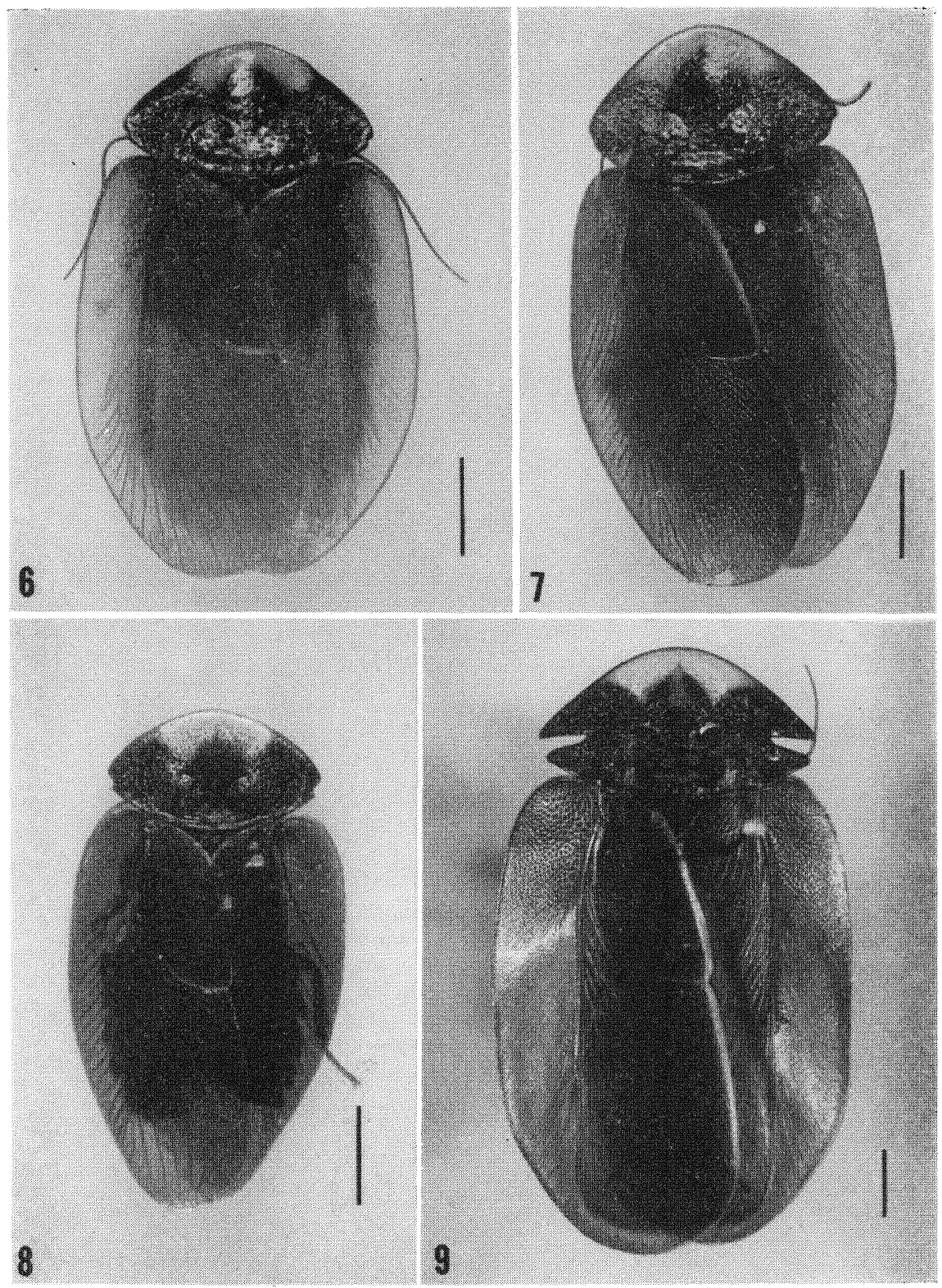

Figs. 6-9. 6. (5 ANSP). Lanxoblatta lata (Shelford). Muzo, Boyacá, Colombia (det. Hebard). 7. (4 ANSP). Lanxoblatta frater Hebard. Paratype. Antioquia, Colombia. 8. (2 ANSP). Lanxoblatta emarginata (Burm.). La Forestière, Haut Maroni, French Guiana (det. Hebard). 9. (97 ANSP). Schizophilia fissicolis (Serv.). La Forestière, Haut Maroni, French Guiana. (det. Hebard). (scale $=5 \mathrm{~mm}$.) 

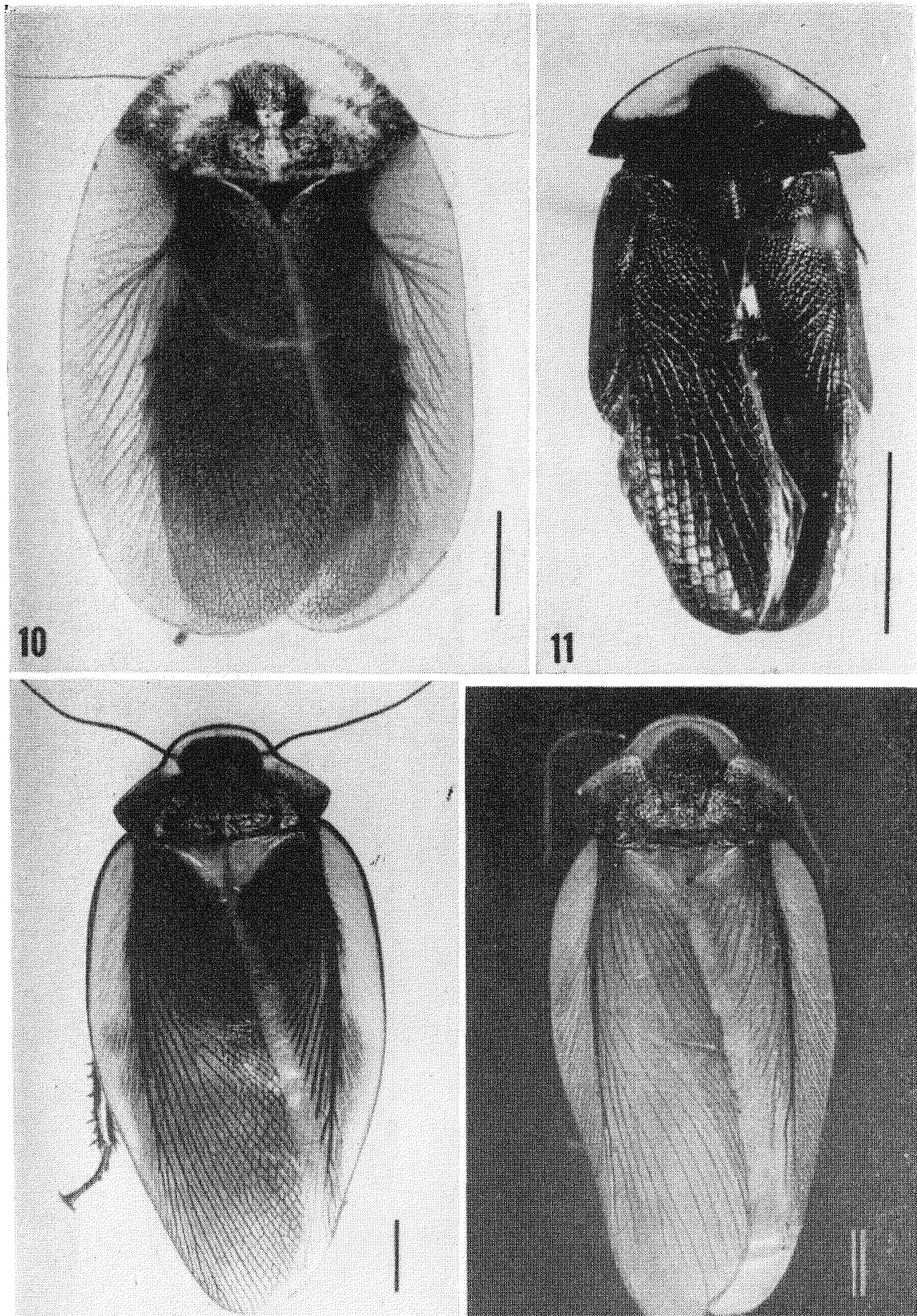

12

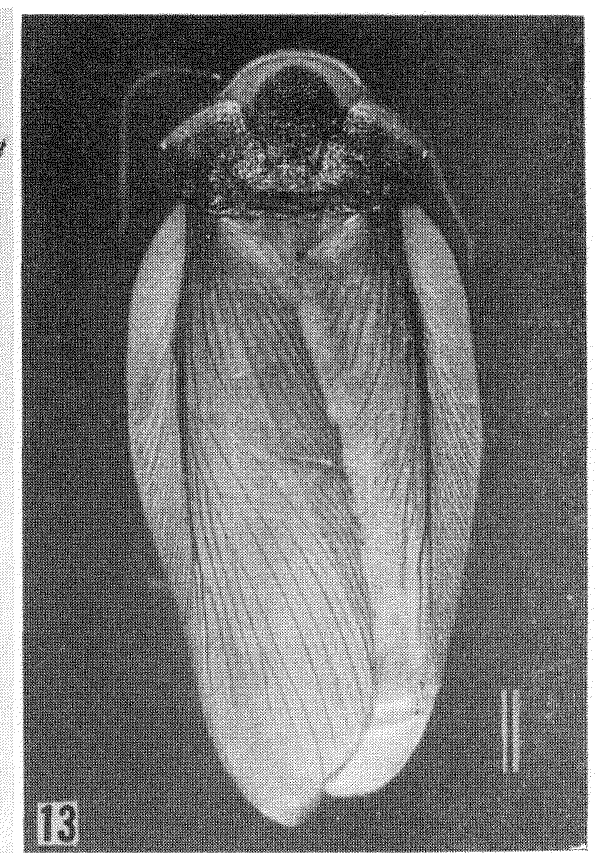

Figs. 10-13. 10. (N). Capucina patula (Walker). Costa Rica (det. Gurney). 11. (102 ANSP). Zetoborella gemmicula Hebard. Topotype. St. Jean du Maroni, French Guiana. 12. (N.) Phortioeca phoraspoides (Walker). Panama. (det. Gurney). 13. (98 ANSP). Phortiocca peruana Sauss. Marcapata, Peru. (scale $=5 \mathrm{~mm}$.) 

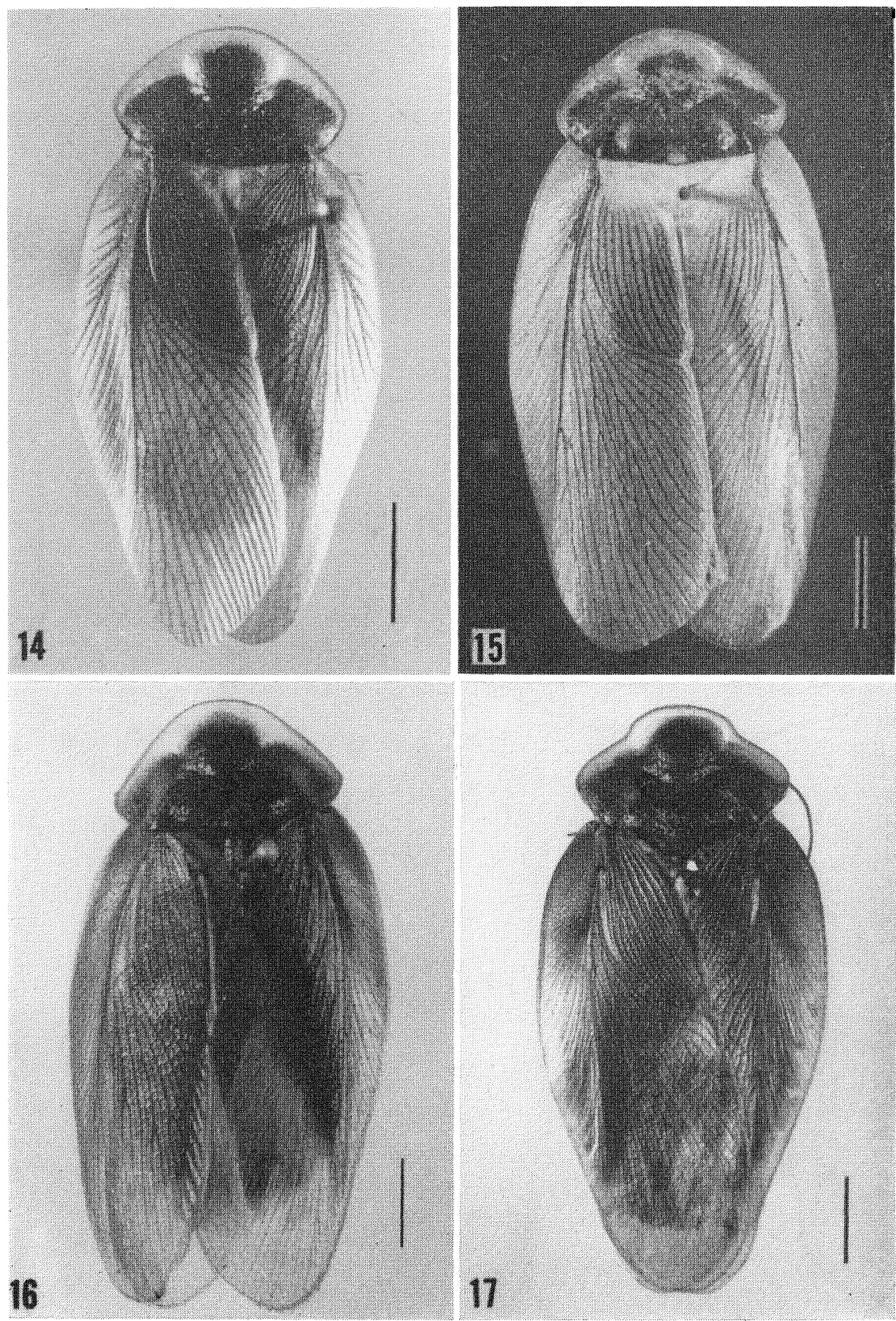

Figs. 14-17. 14. (101 ANSP). Phortioeca nimbata (Burm.). St. Jean du Maroni, French Guiana. 15. (100 ANSP). Phortioeca apolinari Hebard. Paratype. Villavicencio, Colombia. 16. (2 CUZM). Phort oeca verrucosa (Sauss.). Riacho del Pra. (det. Princis). 17. (5 BMNH). Ploritoeca maximiliani (Sauss.). Cahabon, Vera Paz, Mexico. (scale $=5 \mathrm{~mm}$.) 

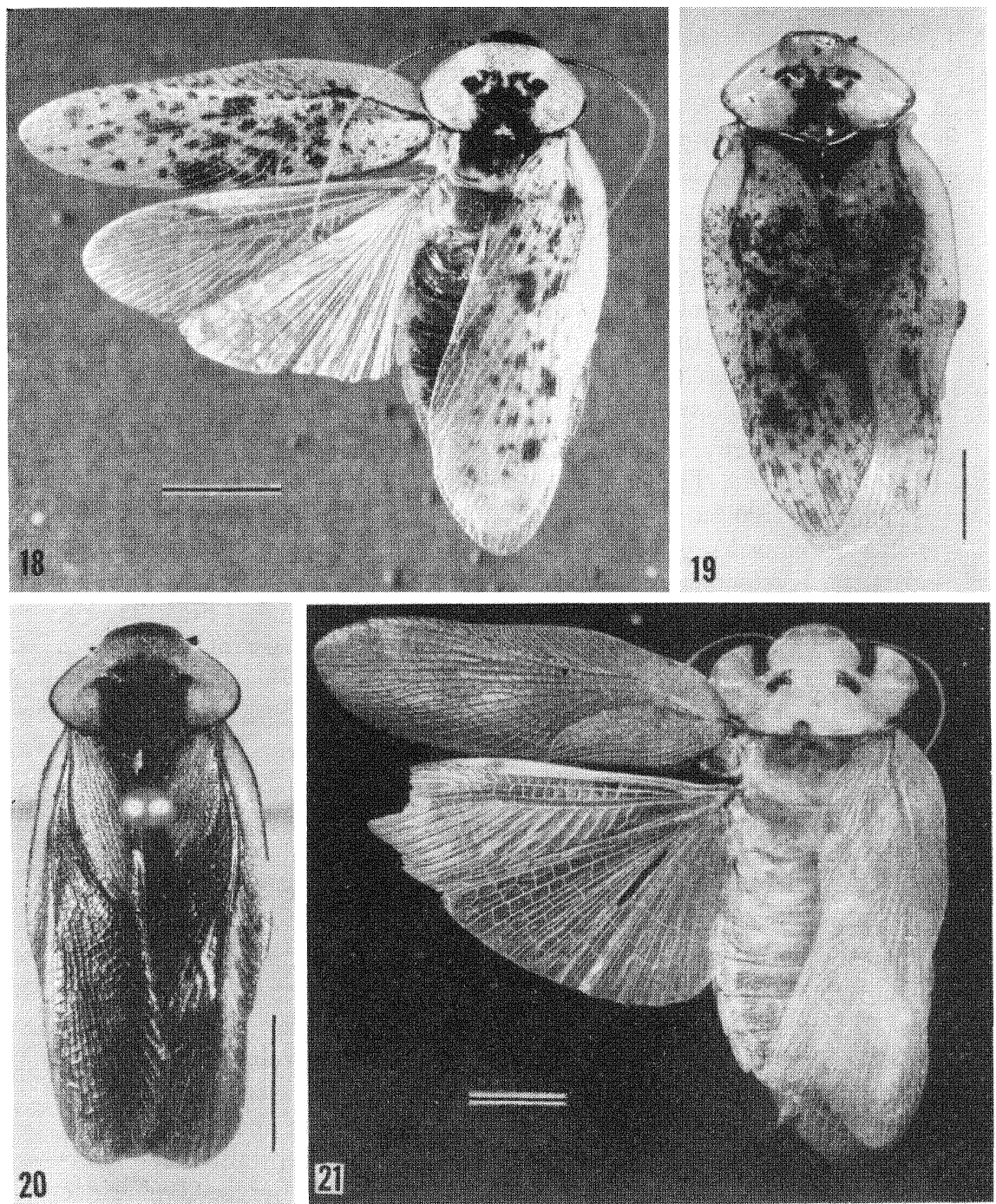

Figs. 18-21. 18. (104 ANSP). Tribonium conspersum (Guérin). Nova Teutonia, Brazil. 19. (103 ANSP). Tribonium colombicum Hebard. Paratype. "New Grenada" (= Colombia). 20. (73 MCZ). Tribonium sp. Brazil. 21. (115 ANSP). Schistopeltis peculiaris Rehn. Holotype 5244. Porto Velho, Rio Madeira, Brazil. (scale $=5 \mathrm{~mm}$.) 
greatly reduced and poorly developed or sclerotized. Most Panchlora lack an $L_{2} d$ and $R_{2}$, and $L_{I}$ is usually represented by a weakly sclerotized cleft.

In erecting the genus Phortioecoides, Rehn (I937, p. 234) stated that it is "Related to Phortioeca Saussure, Capucinella Hebard, and Capucina Saussure, showing certain features of agreement with each, but differing from each one by combinations of characters." The genitalia of Capucinella ( $\mathrm{L}_{2} \mathrm{~d}$ and $\mathrm{R}_{2}$ ) show none of the typical characters of Zetoborinae; the genus probably belongs in the Epilamprinae. The shape of Lad of Phortioecoides (Fig. 37) more closely approaches that of Zetobora (Figs. 22, 27, 28) and I place Phortioecoides closer to this genus than to Capucina.

2. Phortioecini (Capucina, Lanxoblatta, Phortioeca, Schizopilia, and Zetoborella, Figs. 6-I7, 40-98). L2d (Figs. 40, 43, 45, 48, 50, $5 \mathrm{I}, 54,57,60-62,63,66-70,72,75,78,81,84)$ is considerably more developed and robust than in the Zetoborini, and reaches its greatest development in certain species of Phortioeca (Figs. 87, 90, 93, 96-98). R2 has a well defined subapical incision (Figs. 4I, 44, $46,52,55,58,64,71)$ except for several species of Phortioeca (Figs. 73, 76, 79, 82, 85).

Hebard (I92I, p. 210) compared Zetoborella with Zetobora spp. The genitalia of Zetoborella (Figs. 4O, 4I) are closer to other members of the Phortioecini (e.g. Figs. 43-46) than to Zetobora.

Capucina patula (Fig. Io) was placed in the Panchlorinae by McKittrick (1964) and in the Laxtinae by Princis (1960). The Laxtinae of Princis is not recognized by McKittrick and she has assigned several of the genera in this grouping to other subfamilies. Princis (personal communcation) regards his subfamily Laxtinae ". . . as provisional. Further study will probably show that it is not at all a homogeneous group and must be sooner or later split up." McKittrick used proventricular and female genitalic characters in placing Capucina in the Panchlorinae. However many of the character differences she used in comparing ovipositors and proventriculi seem to be very subtle, and I believe the male genitalia offer characters which show more clear cut relationships in the Blaberidae than do the proventriculus or ovipositor. Miller ( I969) found that the morphological diversity of the proventriculus in 9 subfamilies of Blaberidae ". . . often defied the most dedicated efforts to group them into subfamilies." The male genitalia of Capucina are so similar basically to those of other members of the Phortioecini that I do not hesitate to assign this genus to the Zetoborinae. 

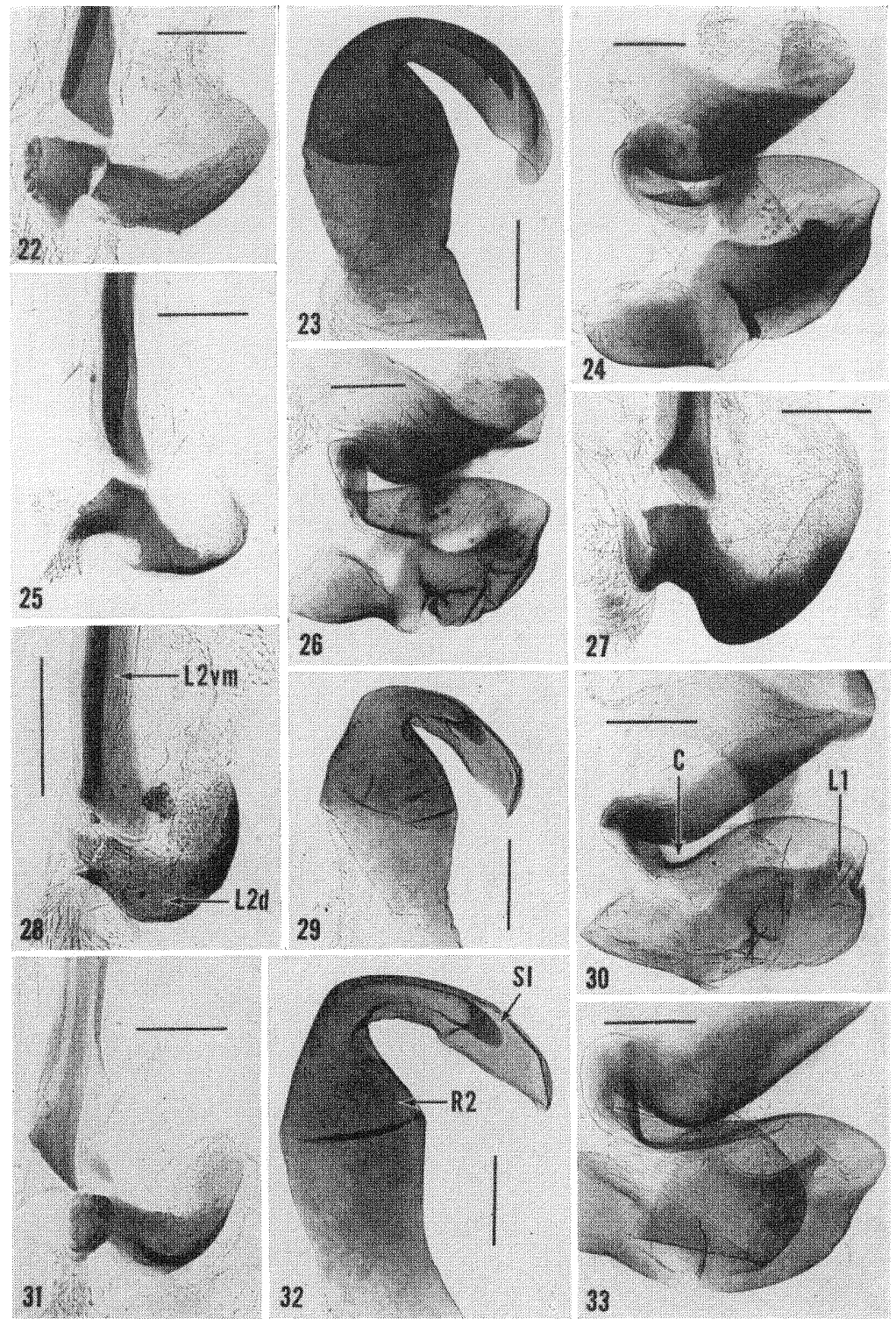

Figs. 22-33. 22-24. (179 USNM). Zetobora signaticollis. Santo Amaro, São Paulo, Brazil. (det. Gurney). 25-26. (180 USNM). Z. signaticollis. Santo Amaro, São Paulo, Brazil. 27. (181 USNM), Zetobora sp. Serra Caraça, M. G. Brazil. 28-30. (6 BMNH), Zetobora transversa. (from adult shown in Fig. 2). 31-33. (7 BMNH). Zetobora monastica. (from adult shown in Fig. 4). L1 $=$ first sclerite of left phallomere; $\mathrm{C}=$ cleft of $\mathrm{L} 1$; L2vm $=$ median sclerite ( $\mathrm{L} 2$ ventromedial) ; L2d $=$ dorsal sclerite of $\mathrm{L} 2$; $\mathrm{R} 2$ = hooked sclerite of right phallomere; SI = subapical incision of R2. (scale $=0.2 \mathrm{~mm}$.) 

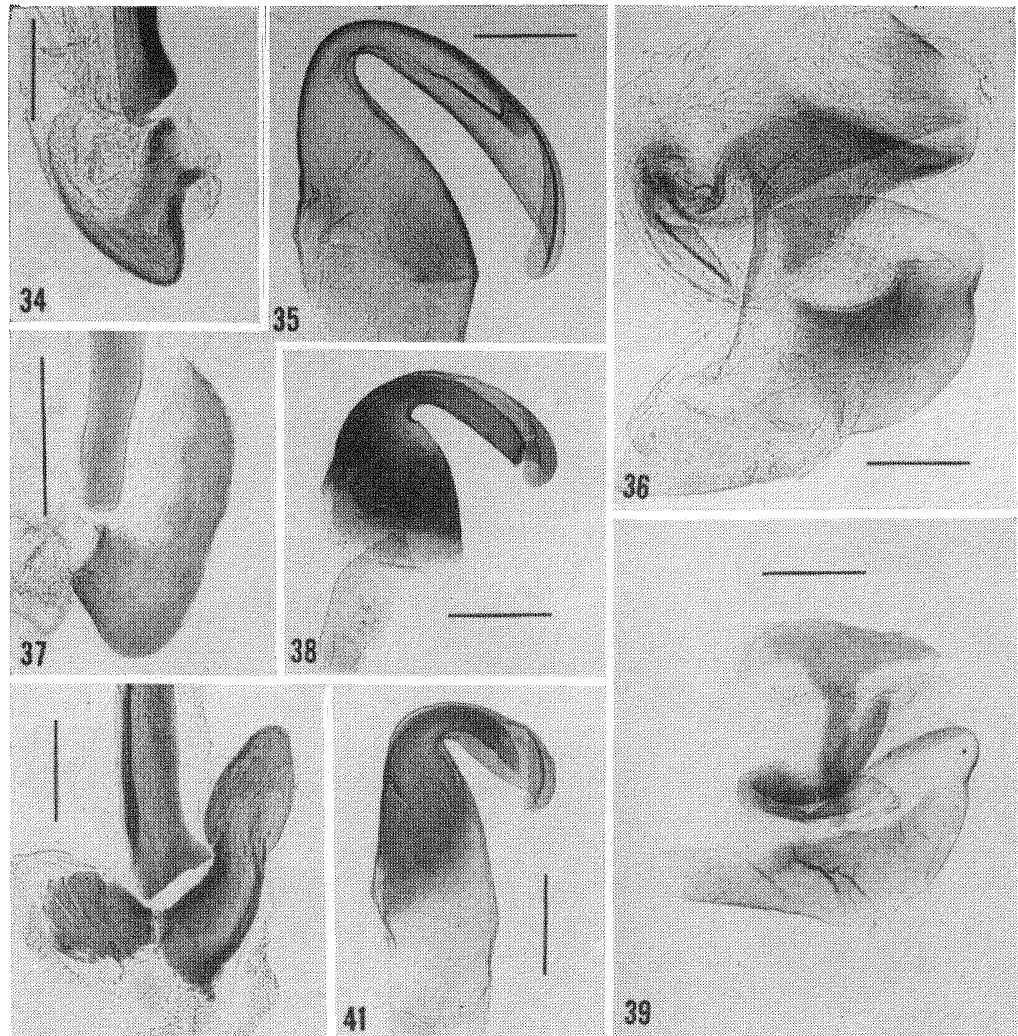

40
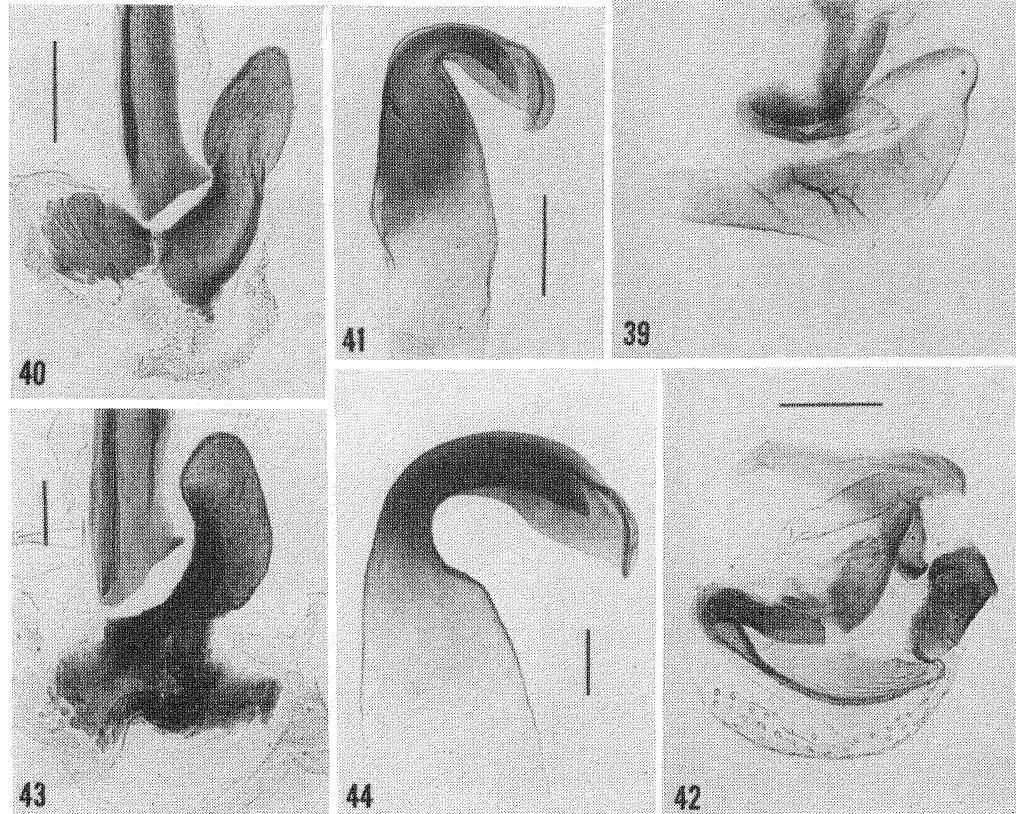

Figs. 34-44. 34-36. (106 ANSP). Zetobora ampla. (from adult shown in Fig. 3; Fig. 34 is a ventral view). 37-39. (113 ANSP). Phortioecoides guarani. (from adult shown in Fig. 5). 40-42. (102 ANSP). Zetoborella gemmicula. (from adult shown in Fig. 11). 43-44. (97 ANSP). Schizopilia fissicollis. (from adult shown in Fig. 9). (scale $=0.2 \mathrm{~mm}$.) 

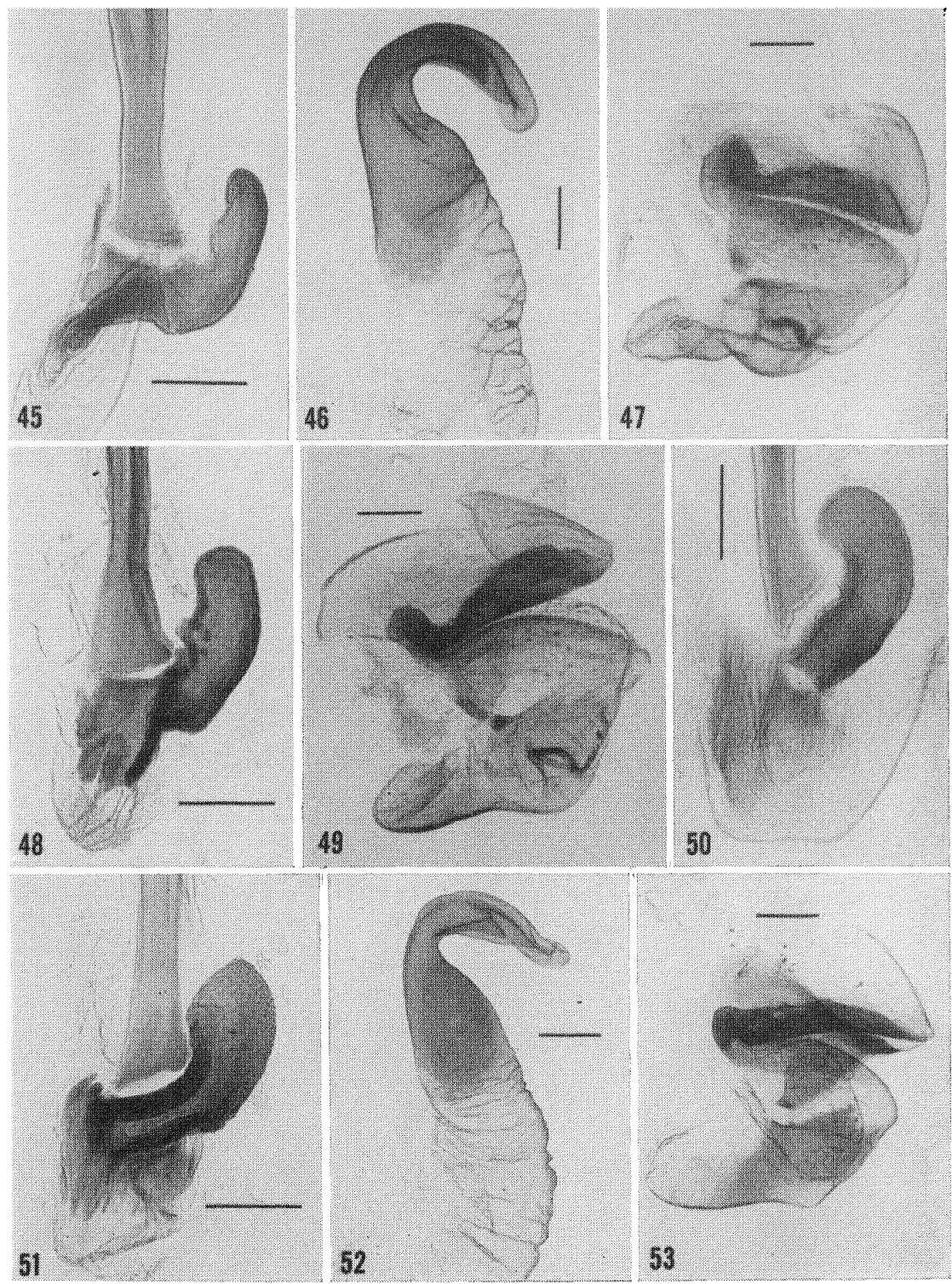

Figs. 45-53. 45-49. Lanxoblatta frater. 45-47. (3 ANSP). Paratype. Antioquia, Colombia. 48-49. (4 ANSP). (from adult shown in Fig. 7). 50. (1 ANSP). Lanxoblatta lata. Muzo, Boyacá, Colombia. 51-53. (N). Lanxoblatta emarginata. From laboratory colony originating in Flores, Manaus, Amazonas, Brazil. (scale $=0.2 \mathrm{~mm}$.) 

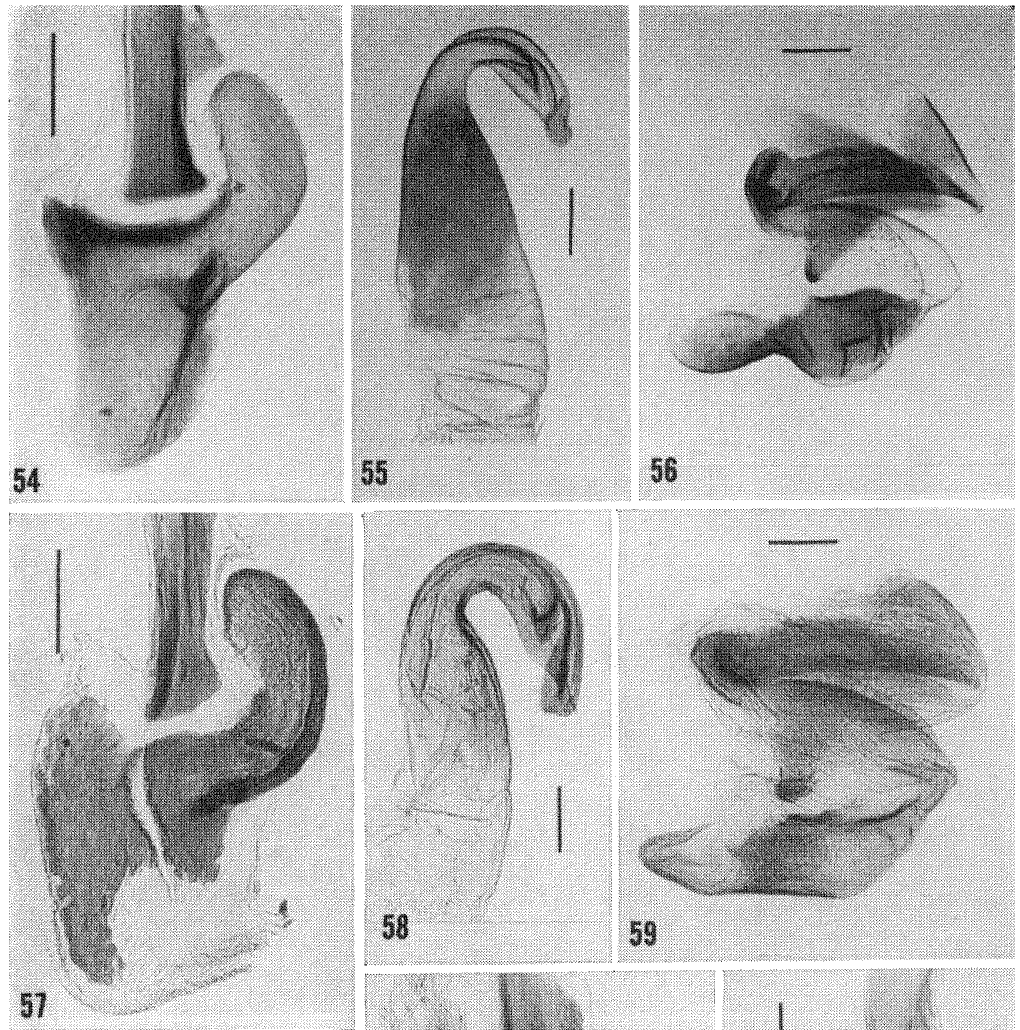

\section{7}
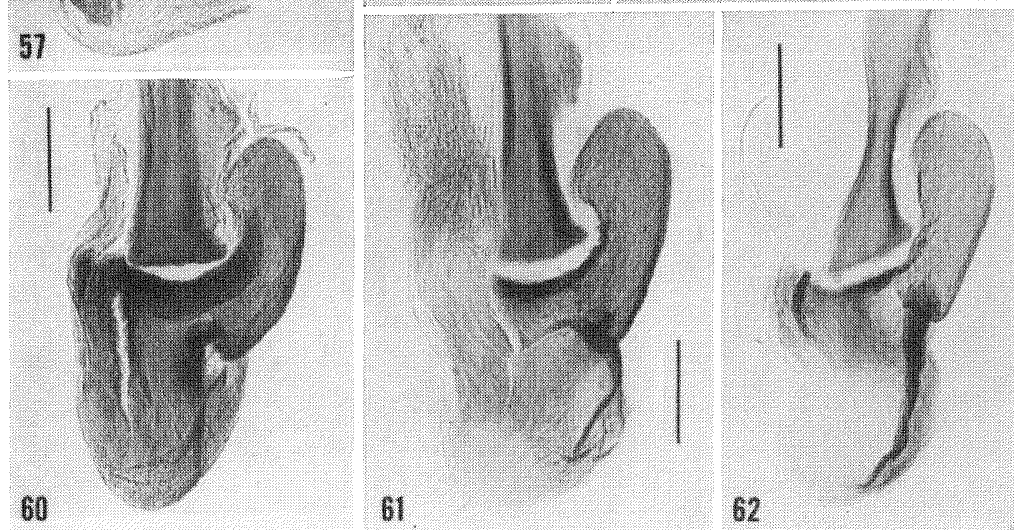

Figs. 54-62. Lanxoblatta emarginata. 54-56. (2 ANSP). (from adult shown in Fig. 8). 57-59. (9 MCZ). Ecuador. 60. (10 MCZ). Probably Brazil. 61. (6 ANSP). St. John du Maroni, French Guiana. 62. (7 ANSP). Antioquia, Colombia. (scale $=0.2 \mathrm{~mm}$.) 

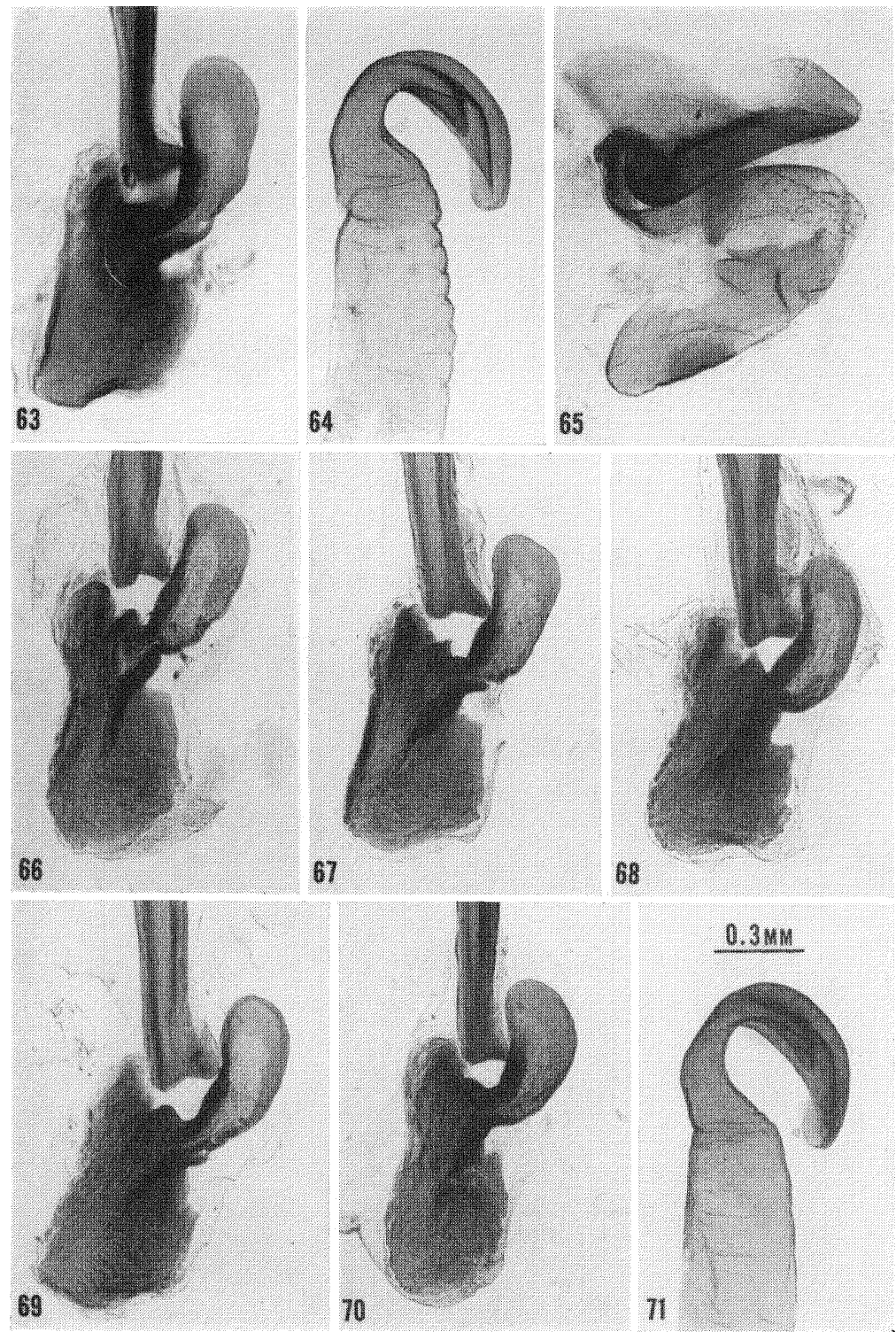

Figs. 63-71. Capucina patula. (N). From a laboratory culture originating in Costa Rica. (all to scale shown in Fig. 71). 

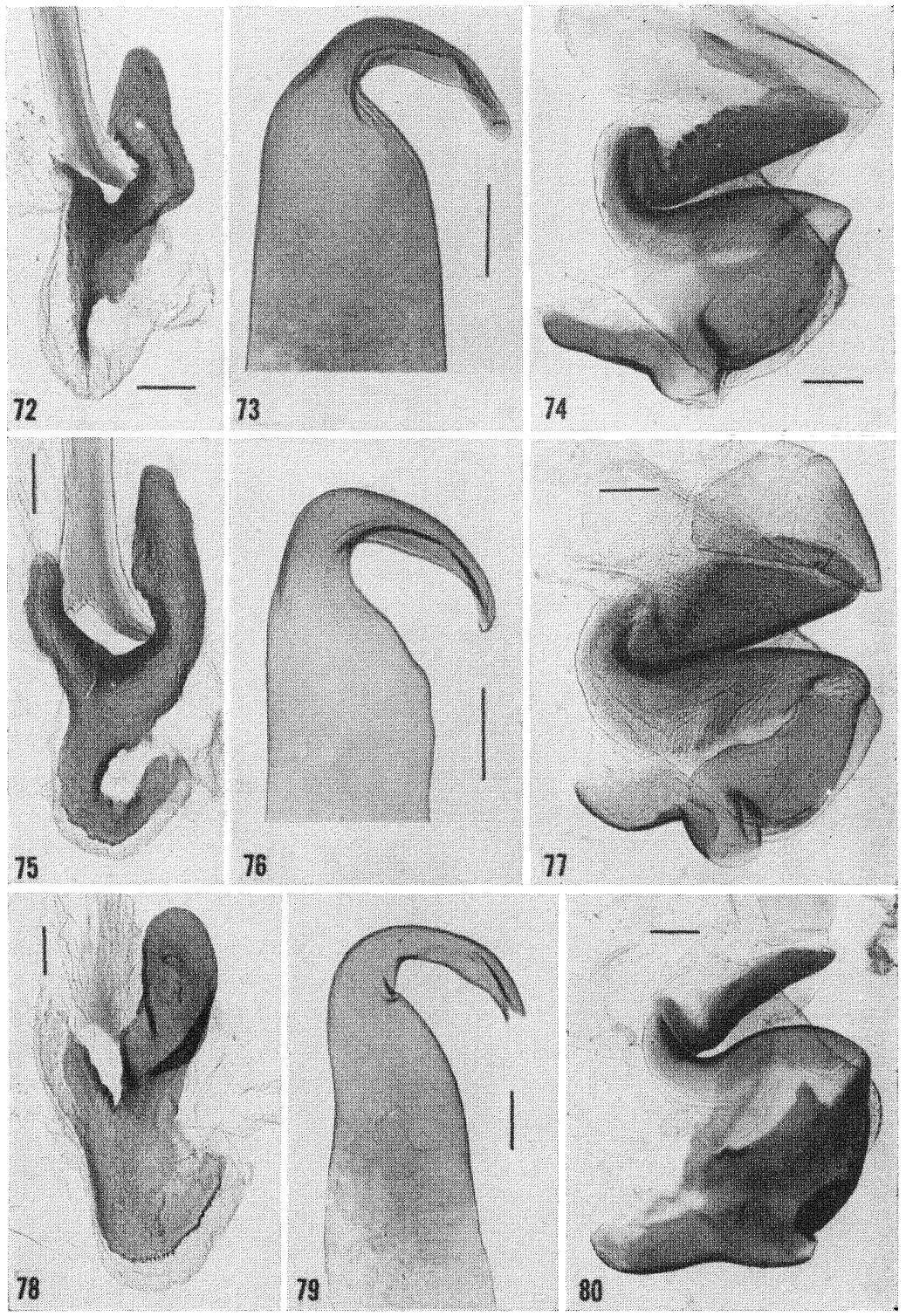

Figs. 72-80. 72-77. Phortioeca nimbata. 72-74. (101 ANSP). (from adult shown in Fig. 14). 75-77. (107 ANSP). La Forestière, Haut Maroni, French Guiana. 78-80. (5 BMNH). Phortioeca max:miliani. (from adult shown in Fig. 17). (scale $=0.2 \mathrm{~mm}$.) 


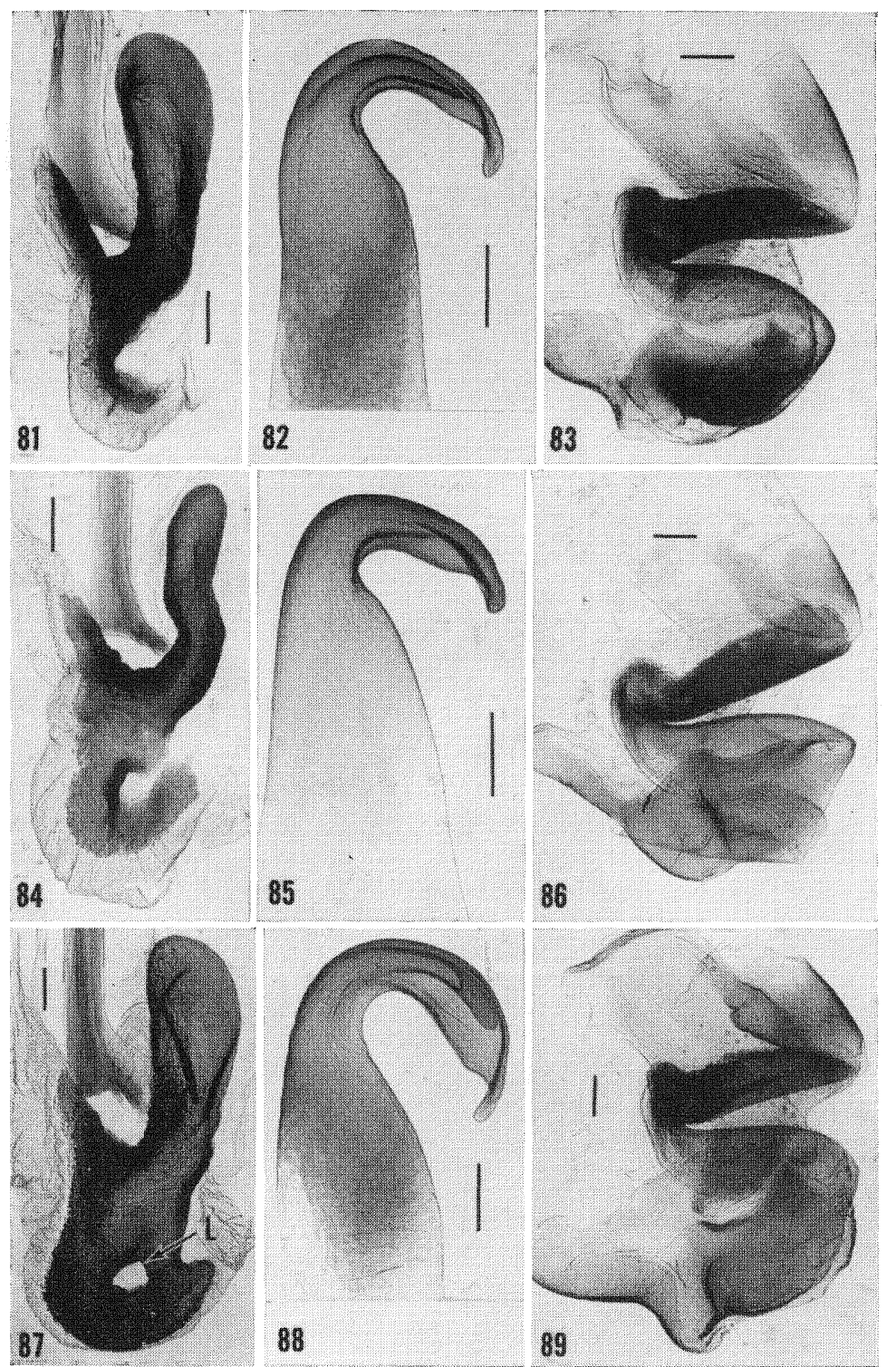

Figs. 81-89. 81-83. (100 ANSP). Phortioeca apolinari. (from adult shown in Fig. 15). 84-86. (2 CUZM). Phortioeca verrucosa. (from adult shown in Fig. 16). 87-89. (98 ANSP). Phortioeca peruana. (from adult shown in Fig. 13). $\mathrm{L}=$ lacuna in sclerotized basal area of L2d. (scale $=$ $0.2 \mathrm{~mm}$.) 


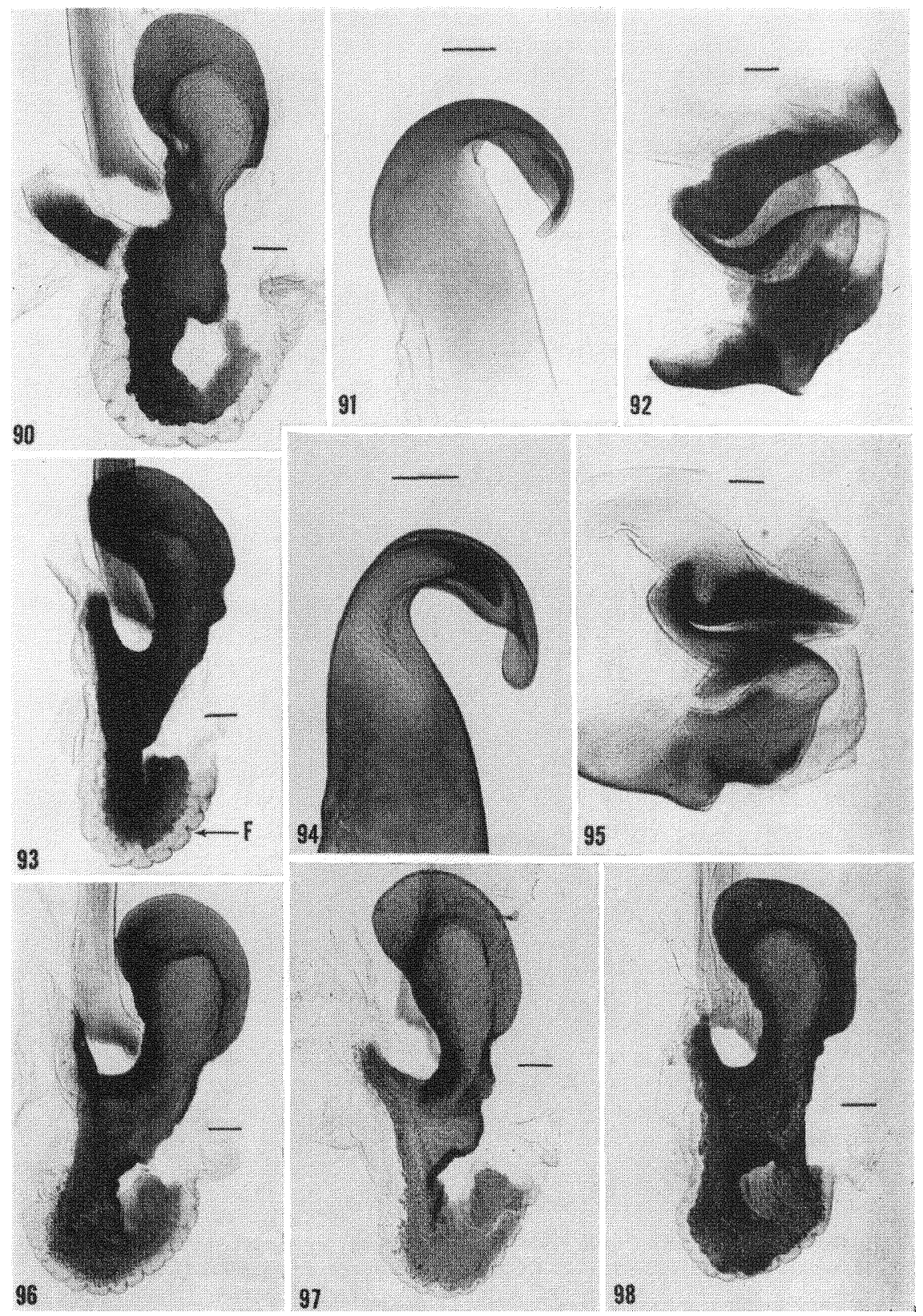

Figs. 90-98. Phort.oeca phoraspoides (Walker). 90-92. (99 ANSP). Muzo, Colombia (det. Hebard). 93-98. (N). Laboratory culture originating from Panama. $\mathrm{F}=$ fringe around preputial membrane. (scale $=0.2 \mathrm{~mm}$.) 
In Phortioeca peruana (Fig. 87) and P. phoraspoides (Fig. 98), the sclerotization of the preputial membrane, which forms the base of L2d, may be incomplete leaving a lacuna or window. However, it is clear that this character is variable (Figs. 90, 93, 96-98) and cannot be used for specific determination. In $P$. phoraspoides the rounded margin of the preputial membrane which surrounds the sclerotized base of L2d has more or less uniformly spaced indentations (Fig. 93) which are absent in other species of Phortioeca examined.

Based on the shape of $\mathrm{R} 2$, Phortioeca nimbata, maximiliani, apolinari, and verrucosa can be grouped together. In these species the curved hook portion of $R_{2}$ is relatively narrow and its subapical incision is poorly developed or absent (Figs. 73, 76, 79, 82, 85). Phortioeca peruana and $P$. phoraspoides both have stouter and more robust R2's and the subapical incisions (Figs. 88, 94) are distinct.

Rehn (1932) stated that the genera Zetobora, Lanxoblatta, Zetoborella, and Schizopilia ". . . are clearly derivatives of a single phylum," whereas Schistopeltis and Tribonium ". . . typifies a distinct and clearly marked phylogenetic series." In general the male genitalia tend to support Rehn's hypothesis. However, I have separated Zetobora from the other 3 genera of his grouping because of the relatively poorly developed L2d.

3. Triboniini (Tribonium and Schistopeltis, Figs. I 8-2 I, 99-I I3). In this tribe, L2vm has a well developed posterior arm or extension (Fig. I05) which extends dorsally (laterally in the photographs because of flattening) and L2d extends upward and curves towards this outgrowth (Figs. 99, 102, I05, I08, III). The subapical incision of $\mathrm{R}_{2}$ is clearly defined and occurs at about the middle of the hook (Figs. I00, 103, I06, I09, I I2).

\section{Summary}

Based on the shape of $\mathrm{L}_{2} \mathrm{vm}$ and L2d of the male genitalia, 9 genera of Zetoborinae are divided into 3 tribes as follows:

I. Zetoborini (Zetobora and Phortioecoides).

2. Phortioecini (Capucina, Lanxoblatta, Phortioeca, Schizopilia, and Zetoborella).

3. Triboniini (Tribonium and Schistopeltis). 

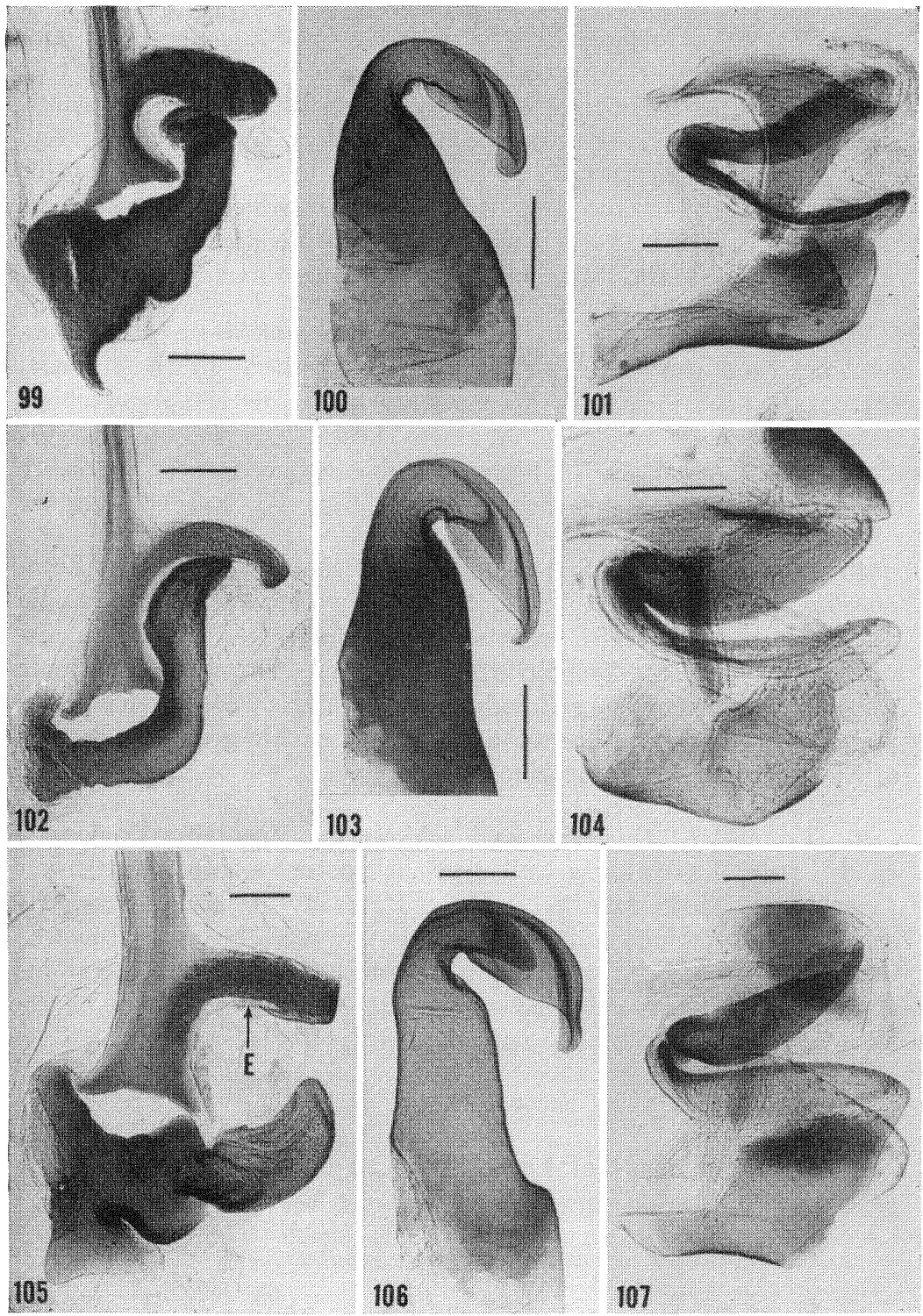

Figs. 99-107. 99-101. (103 ANSP). Tribonium colombicum. (from adult shown in Fig. 19). 102-104. (104 ANSP). Tribonium conspersum (from adult shown in Fig. 18). 105-107. (1 CUZM). Tribonium sp. $\mathrm{E}=$ dorsal extension of $\mathrm{L} 2 \mathrm{vm}$. (scale $=0.2 \mathrm{~mm}$.) 


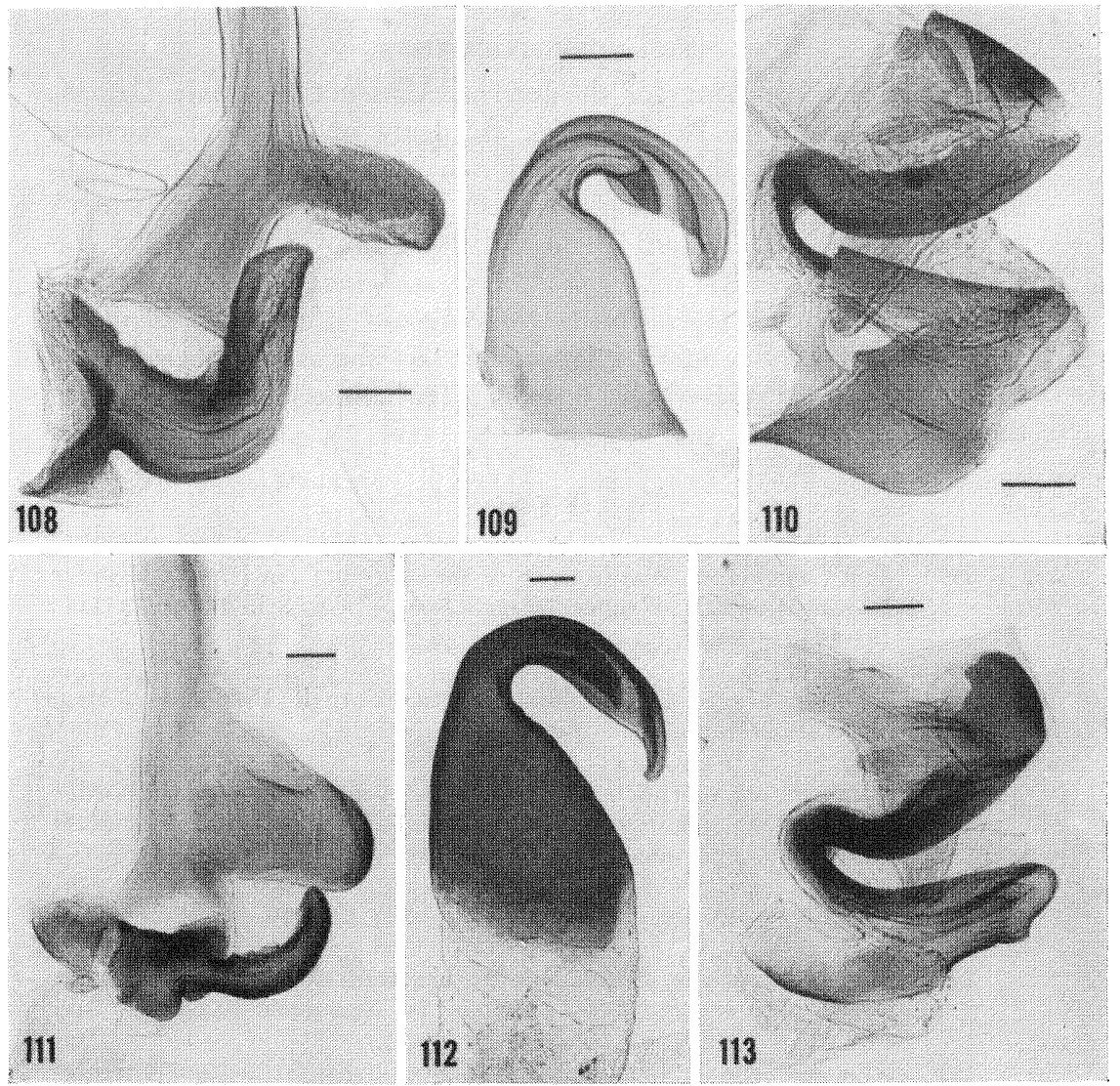

Figs. 108-113. 108-110. Tribonium sp. 108. (73 MCZ). (from adult shown in Fig. 20). 109-110. (31 MCZ). 111-113. (115 ANSP). Schistopeltis peculiaris. (from adult shown in Fig. 21). (scale $=0.2 \mathrm{~mm}$.) 


\section{Acknowledgements}

I thank the following for the loan of Museum material: Dr. M. G. Emsley and Dr. N. D. Jago, Academy of National Sciences, Philadelphia; Dr. Ashley Gurney, U. S. National Museum, Washington, D.C.; Dr. D. R. Ragge, British Museum (Natural History) London; Dr. S. L. Tuxen, Zoological Museum, Copenhagen. I collected living specimens of Lanxoblatta emarginata during Phase C of the Alpha Helix expedition to the Amazon in 1967. I thank the National Science Foundation for support on the Amazon expedition under Grant NSF-GB-5916. I thank Mr. Samuel Cohen for taking the photographs.

\section{REFERENCES}

Hebard, M.

1921. South American Blattidae from the Museum National d'Histoire Naturelle, Paris, France. Proc. Acad. Nat. Sci. Phil., 73 (II) : 193-304.

McKitTrick, F. A.

1964. Evolutionary studies of cockroaches. Cornell Univ. Agr. Exp. Sta. Memoir 389, 197 pp.

MilLER, H. K.

1969. Comparative morphological studies of proventriculi in the Order Dictyoptera: suborder Blattaria. Ph.D. Thesis, The Ohio State

Princis, K. University, Columbus, Ohio, 91 pp.

1960. Zur systematik der Blattarien. Eos, 36: 427-449.

ReHN, J. A. G.

1932. Wissenschaftliche Ergebnisse der Schwedischen entomologischen Reisen des Herrn Dr. A. Roman in Amazonas 1914-1915 and 1923-1924. Arkiv för Zoologi, 24A, 1-73.

1937. New or little known neotropical Blattidae (Orthoptera). Number four. Trans. Amer. Entomol. Soc. 63 : 207-258.

RoTH, L. M.

1969. The male genitalia of Blattaria. I. Blaberus spp. (Blaberidae: Blaberinae). Psyche, 76: 217-50.

1970. The male genitalia of Blattaria. II. Poeciloderrhis spp. (Blaberidae: Epilamprinae). Psyche, 77 : 104-119.

Roth, L. M. AND A. B. Gurney.

1969. Neotropical cockroaches of the Epilampra abdomennigrum complex; a clarification of their systematics (Dictyoptera, Blattaria). Ann. Entomol. Soc. Amer. 62: 617-27. 

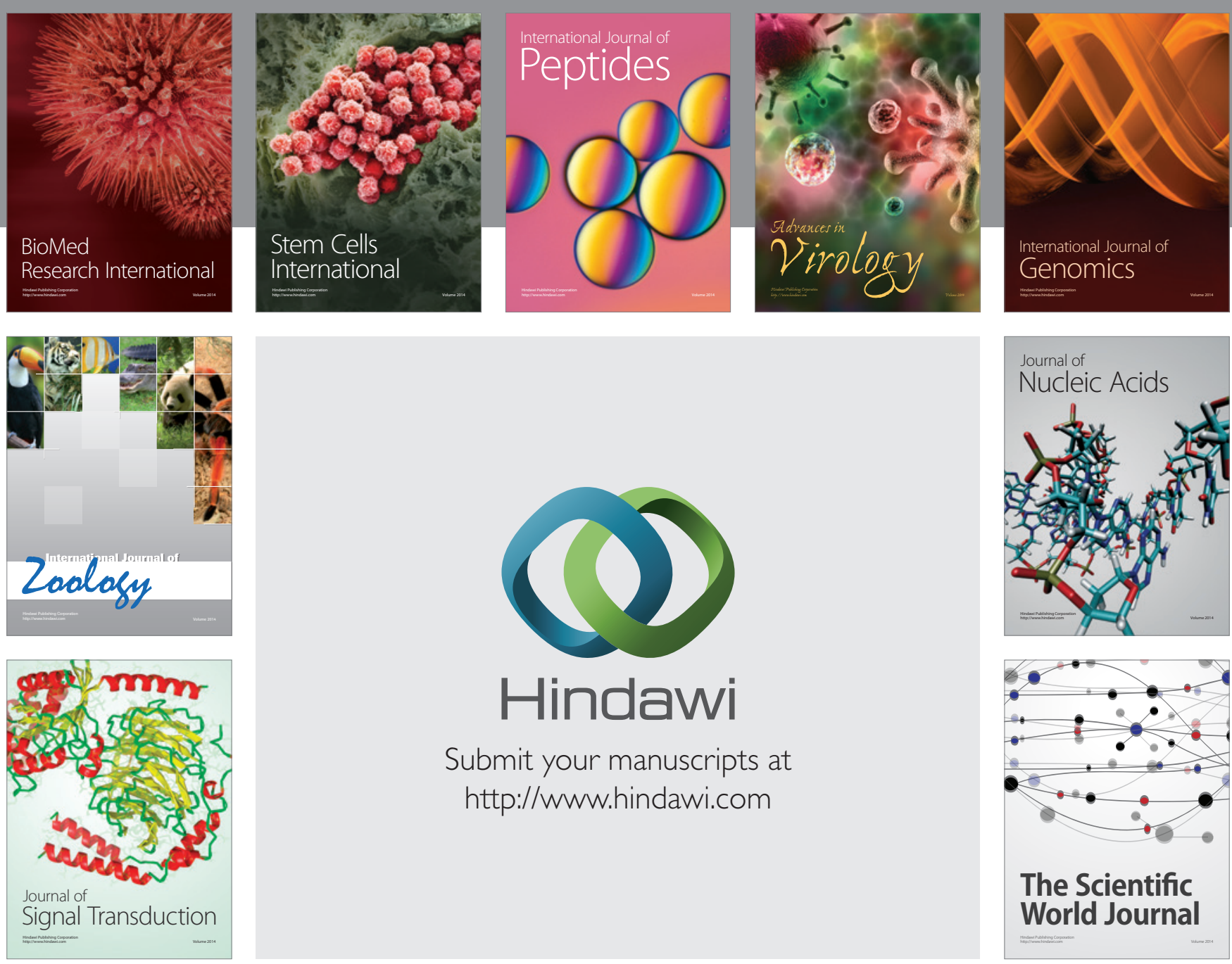

Submit your manuscripts at

http://www.hindawi.com
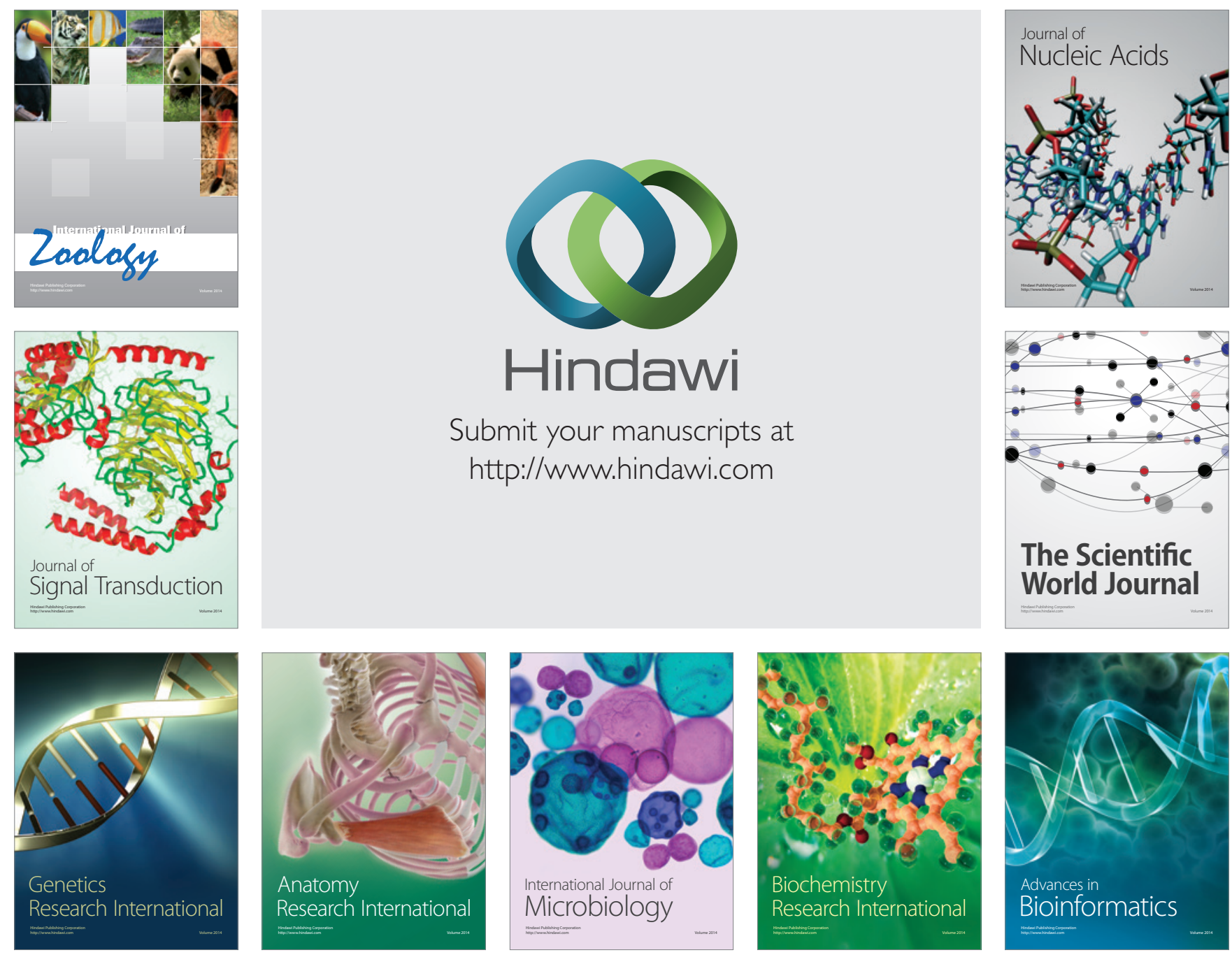

The Scientific World Journal
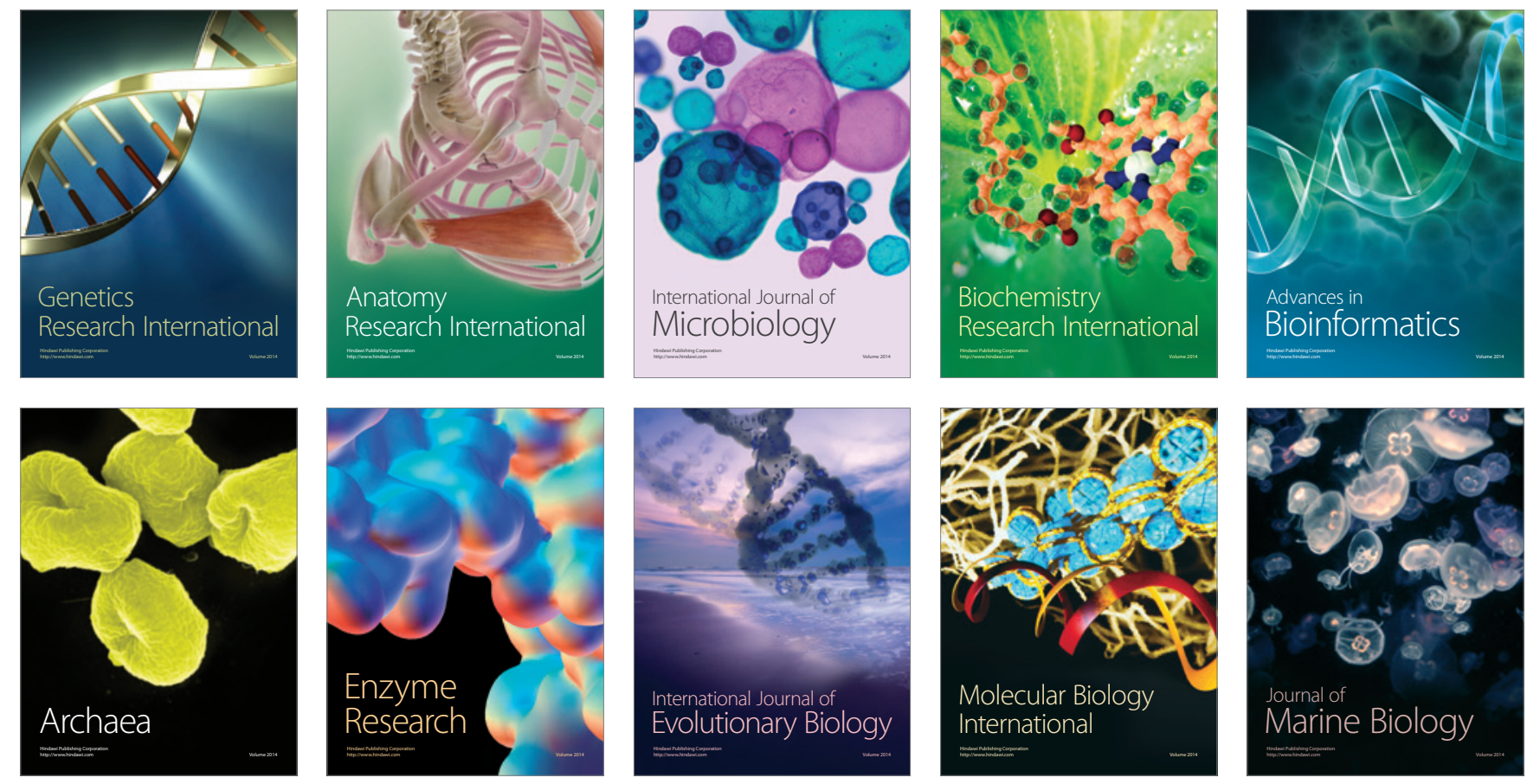